Supplement of Geosci. Model Dev., 13, 3203-3220, 2020

https://doi.org/10.5194/gmd-13-3203-2020-supplement

(C) Author(s) 2020. This work is distributed under

the Creative Commons Attribution 4.0 License.

(c) (i)

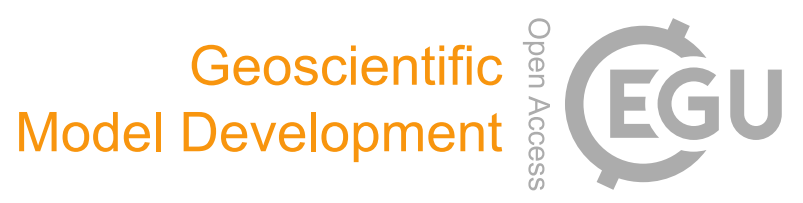

Supplement of

\title{
Global rules for translating land-use change (LUH2) to land-cover change for CMIP6 using GLM2
}

Lei Ma et al.

Correspondence to: Lei Ma (lma6@umd.edu)

The copyright of individual parts of the supplement might differ from the CC BY 4.0 License. 


\section{Supplementary}

Table. S1. Legend translation to produce a common forest canopy cover for various land cover datasets based on (Song et al., 2014). For references see Table. 2.

\begin{tabular}{|c|c|c|}
\hline Products & Land cover class & Fraction \\
\hline \multirow{5}{*}{$\begin{array}{c}\text { GLCC, } \\
\text { MODIS LC }\end{array}$} & Forest (evergreen needleleaf; deciduous needleleaf; evergreen broadleaf; evergreen needleleaf; mixed) & 0.80 \\
\hline & Woody savannas & 0.45 \\
\hline & Cropland/Natural Vegetation Mosaic & 0.25 \\
\hline & Savannas & 0.20 \\
\hline & $\begin{array}{l}\text { Open shrublands; closed shrublands; grasslands; croplands; urban and build-up; snow and ice; water } \\
\text { bodies; permanent wetlands; barren or sparsely vegetated }\end{array}$ & 0 \\
\hline \multirow{6}{*}{ GLC2000 } & Tree cover (evergreen broadleaved, closed deciduous broadleaved) & 0.70 \\
\hline & $\begin{array}{l}\text { Tree cover (evergreen needleleaf; deciduous needleleaf; mixed leaf type; regularly flooded fresh or } \\
\text { saline) }\end{array}$ & 0.575 \\
\hline & Mosaic: Tree cover/other natural vegetation & 0.50 \\
\hline & Tree cover (open deciduous broadleaved) & 0.275 \\
\hline & Mosaic: cropland/tree cover/ other natural vegetation & 0.25 \\
\hline & $\begin{array}{l}\text { Tree cover burnt; shrub cover (evergreen, deciduous); herbaceous cover; sparse herbaceous or sparse } \\
\text { shrub cover; regularly flooded shrub and/or herbaceous cover; cultivated and managed areas; mosaic: } \\
\text { cropland / Shrub and/or grass cover; bare areas; water bodies; snow and ice; artificial surfaces and } \\
\text { associated areas }\end{array}$ & 0 \\
\hline \multirow{10}{*}{ GlobCover } & Closed forest (broadleaved deciduous; needle leaved evergreen) & 0.70 \\
\hline & $\begin{array}{l}\text { Closed to open forest (broadleaved evergreen or semi-deciduous, mixed broadleaved and needle } \\
\text { leaved, broadleaved forest regularly flooded) }\end{array}$ & 0.575 \\
\hline & Open broadleaved deciduous forest/woodland; open needle leaved deciduous or evergreen forest; & 0.30 \\
\hline & Mosaic vegetation (grassland/shrubland/forest) / cropland; mosaic forest or shrubland / grassland & 0.20 \\
\hline & Mosaic grassland / forest or shrubland & 0.175 \\
\hline & Mosaic cropland / vegetation (grassland/shrubland/forest) & 0.117 \\
\hline & $\begin{array}{l}\text { Post-flooding or irrigated croplands (or aquatic); rainfed croplands; closed to open (broadleaved or } \\
\text { needle leaved, evergreen or deciduous); closed to open herbaceous vegetation (grassland, savannas or }\end{array}$ & \multirow{4}{*}{0} \\
\hline & lichens/mosses); sparse vegetation; closed broadleaved forest or shrubland permanently flooded; closed & \\
\hline & to open grassland or woody vegetation on regularly flooded or waterlogged soil; artificial surfaces and & \\
\hline & associated areas; bare areas; water bodies; permanent snow and ice & \\
\hline
\end{tabular}


(a)

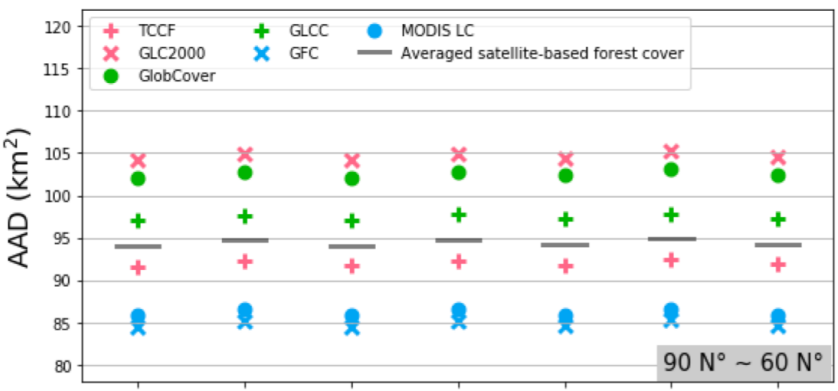

(b)

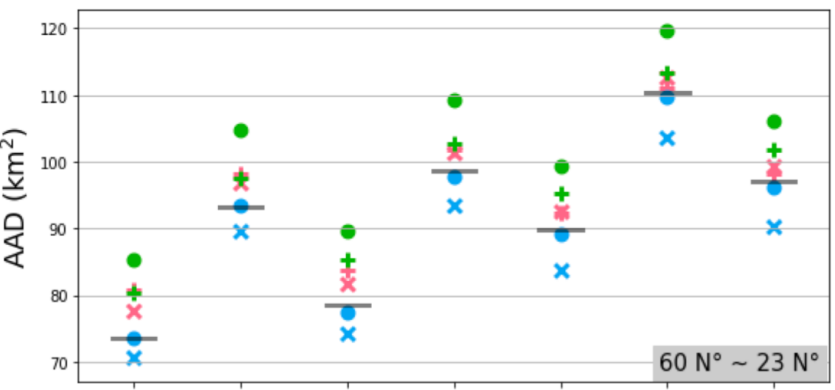

(c)

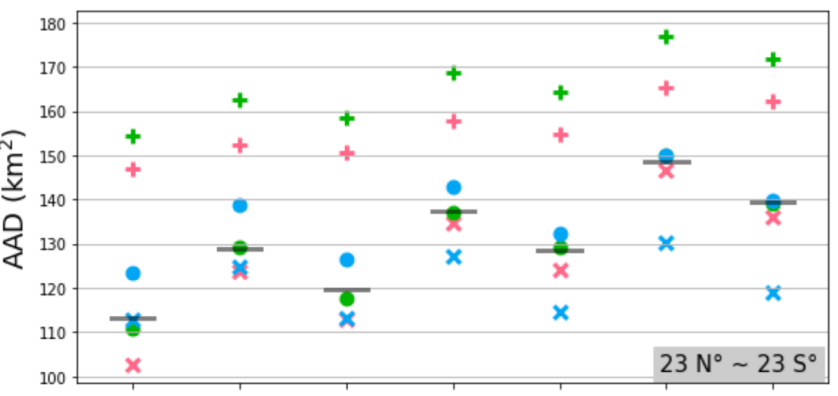

(d)

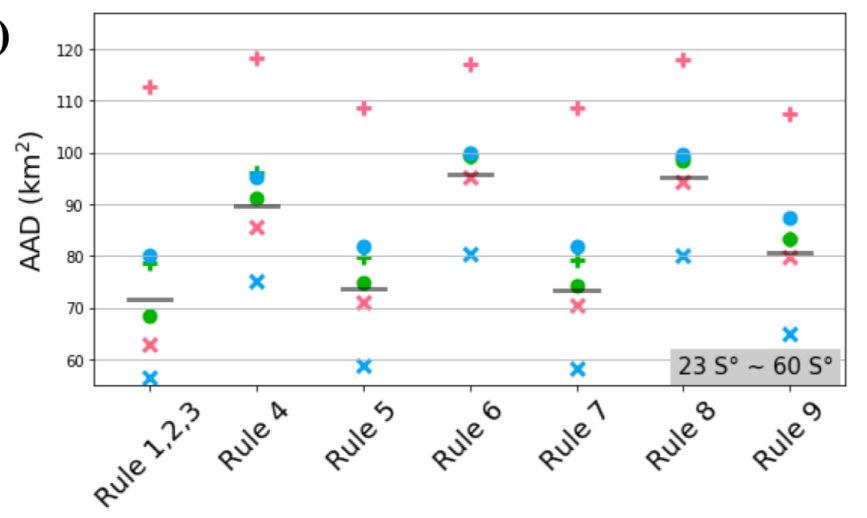

Figure S1. Regional average of absolute difference in forest area between maps estimated by translation rules, and six satellite-based forest cover maps and the averaged satellite-based forest cover map. 

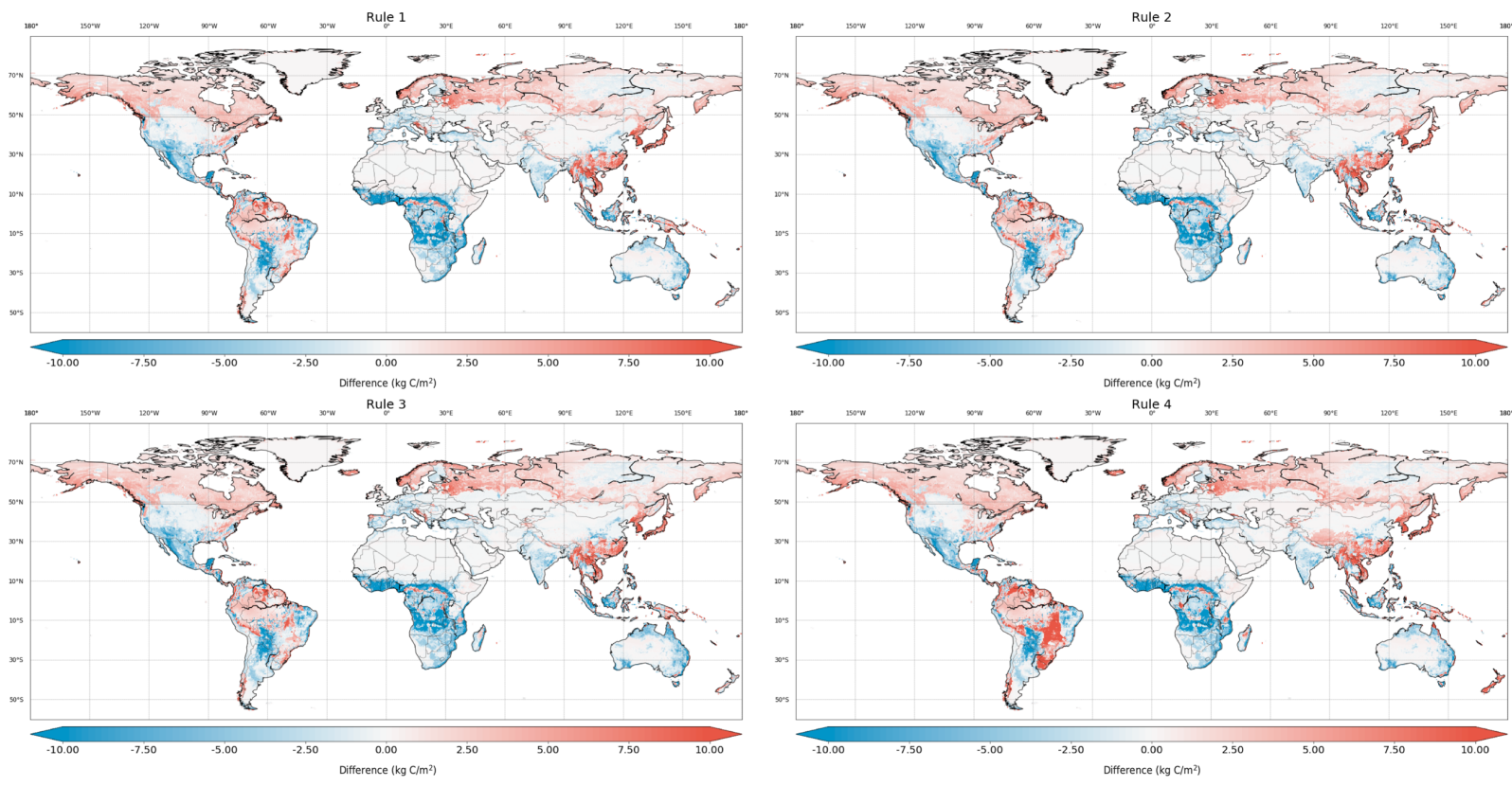

Figure S2. Global carbon density difference between IPCC biomass Tier-1 (Figure 7a) density map and estimates of Rules 1-4 from (a) to (d). 

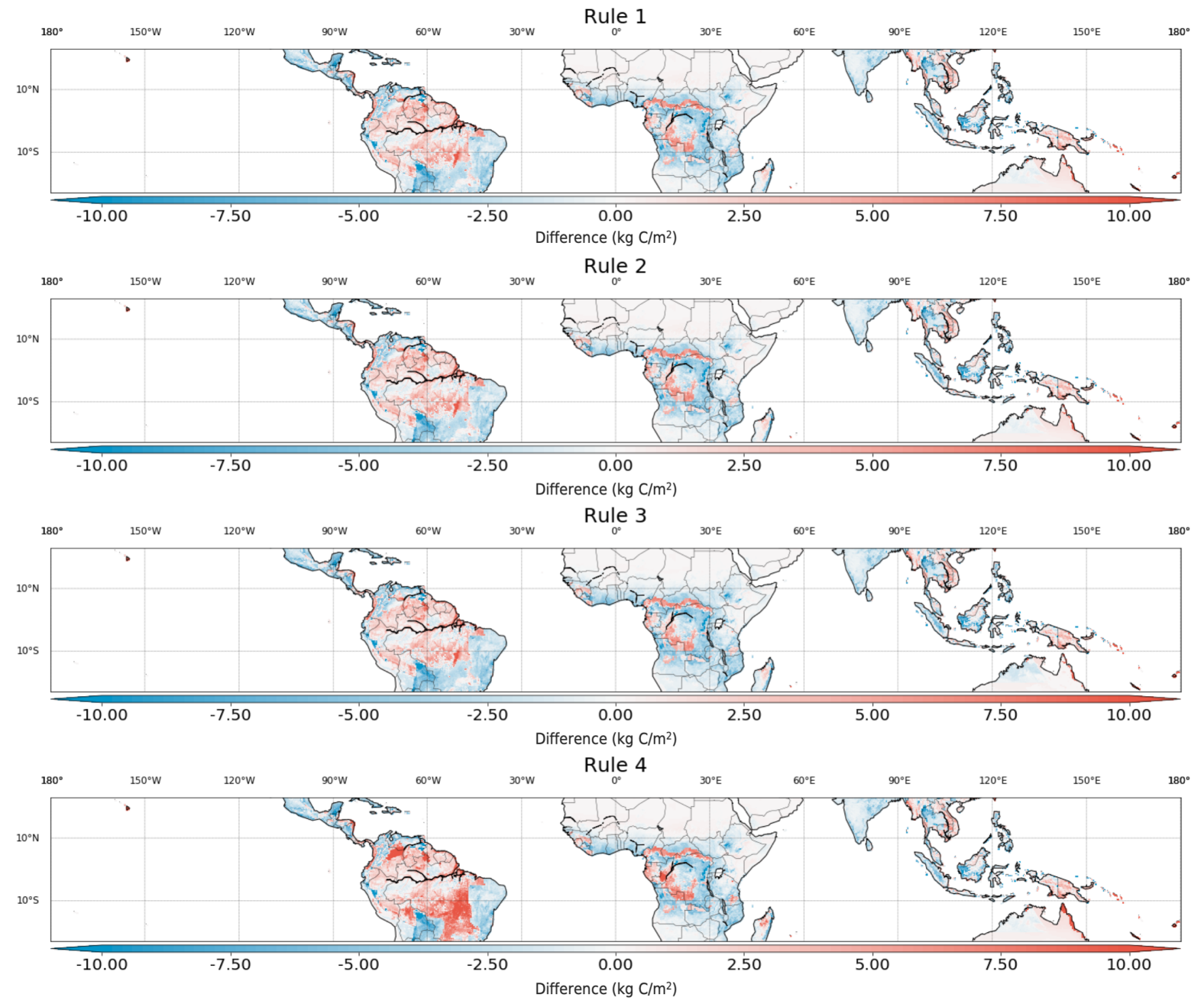

Figure S3. Global carbon density difference between the Baccini's product (Figure 7b) and estimates of Rules 1-4 from (a) to (d). 

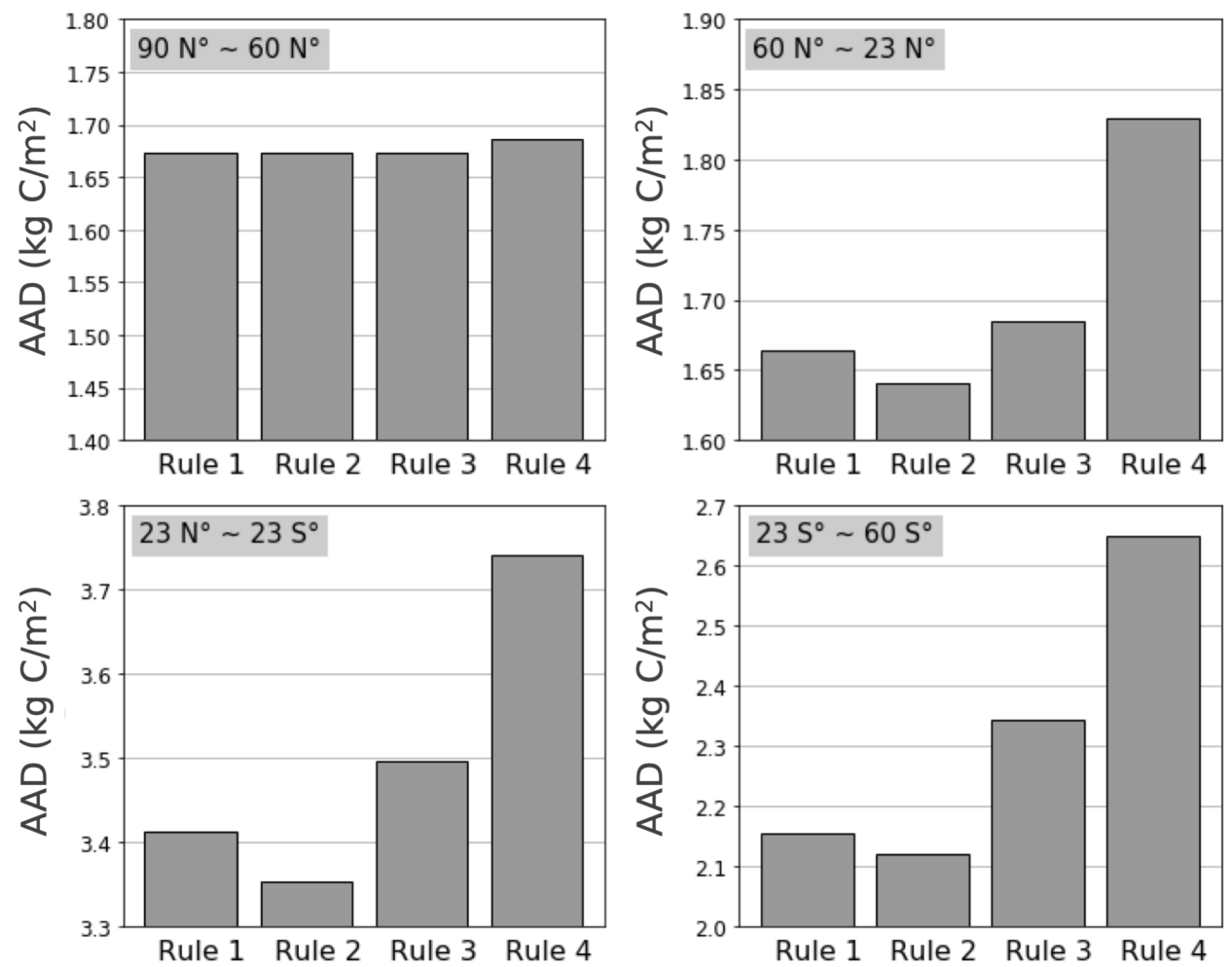

Figure S4. Average of absolute difference in carbon density between estimations of the Rules 1-4 and the IPCC Tier-1 biomass density map at different latitudinal band zones. 
(a)
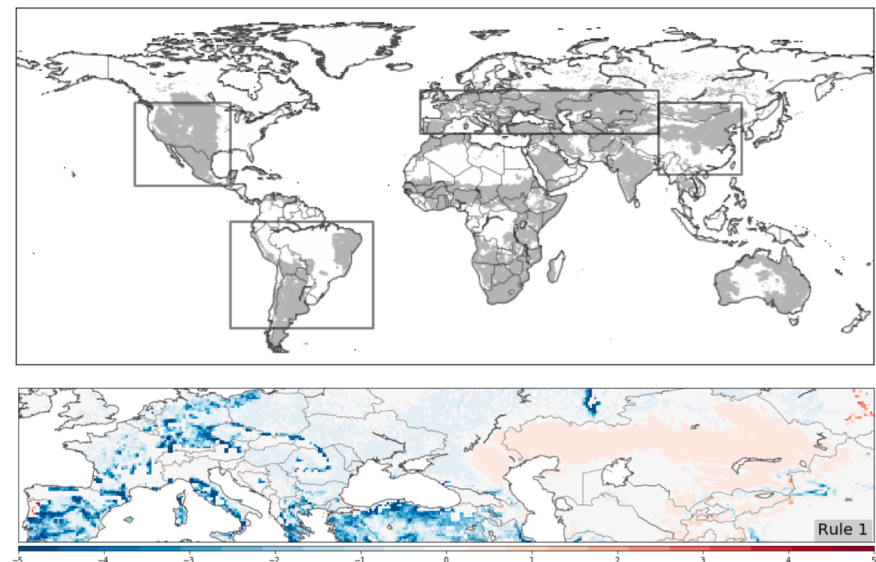

(c)
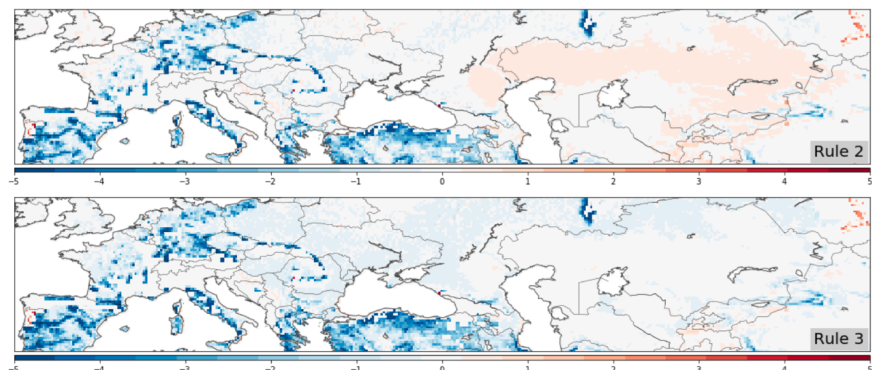

(b)

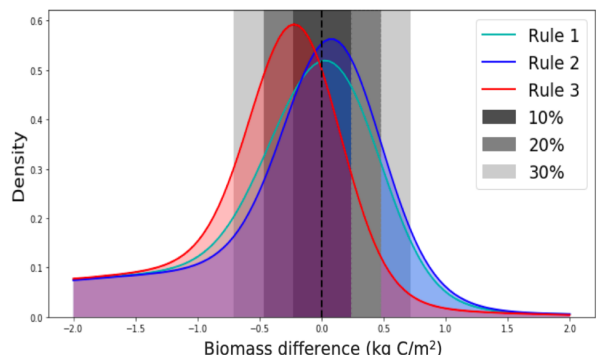

(d)

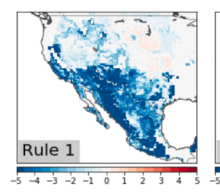

(e)
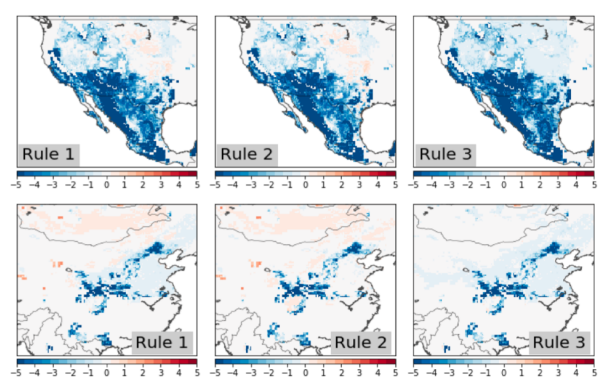

(f)
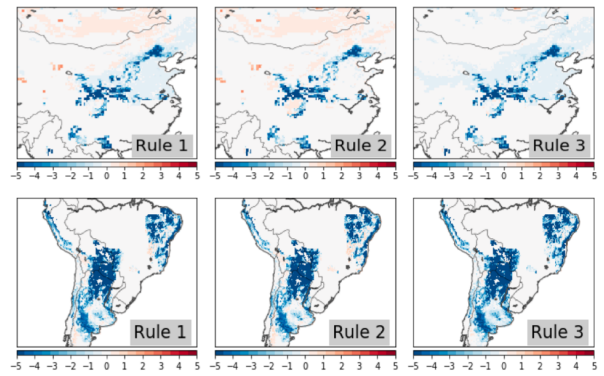

Figure S5. Carbon density difference comparison between the IPCC Tier-1 biomass density map and estimation of Rules 1-3. (a) Shaded regions represent where Rules 1-3 differ in estimates of carbon density; (b) Histogram of carbon density difference of shaded regions in (a), shared bounds present shift range of zero line under three assumed bias levels of the IPCC Tier-1 biomass. (c) - (f) are regional comparison of carbon density difference of Rules 1-3, regions where Rules 1-3 have the same estimate of carbon density are not shown. 

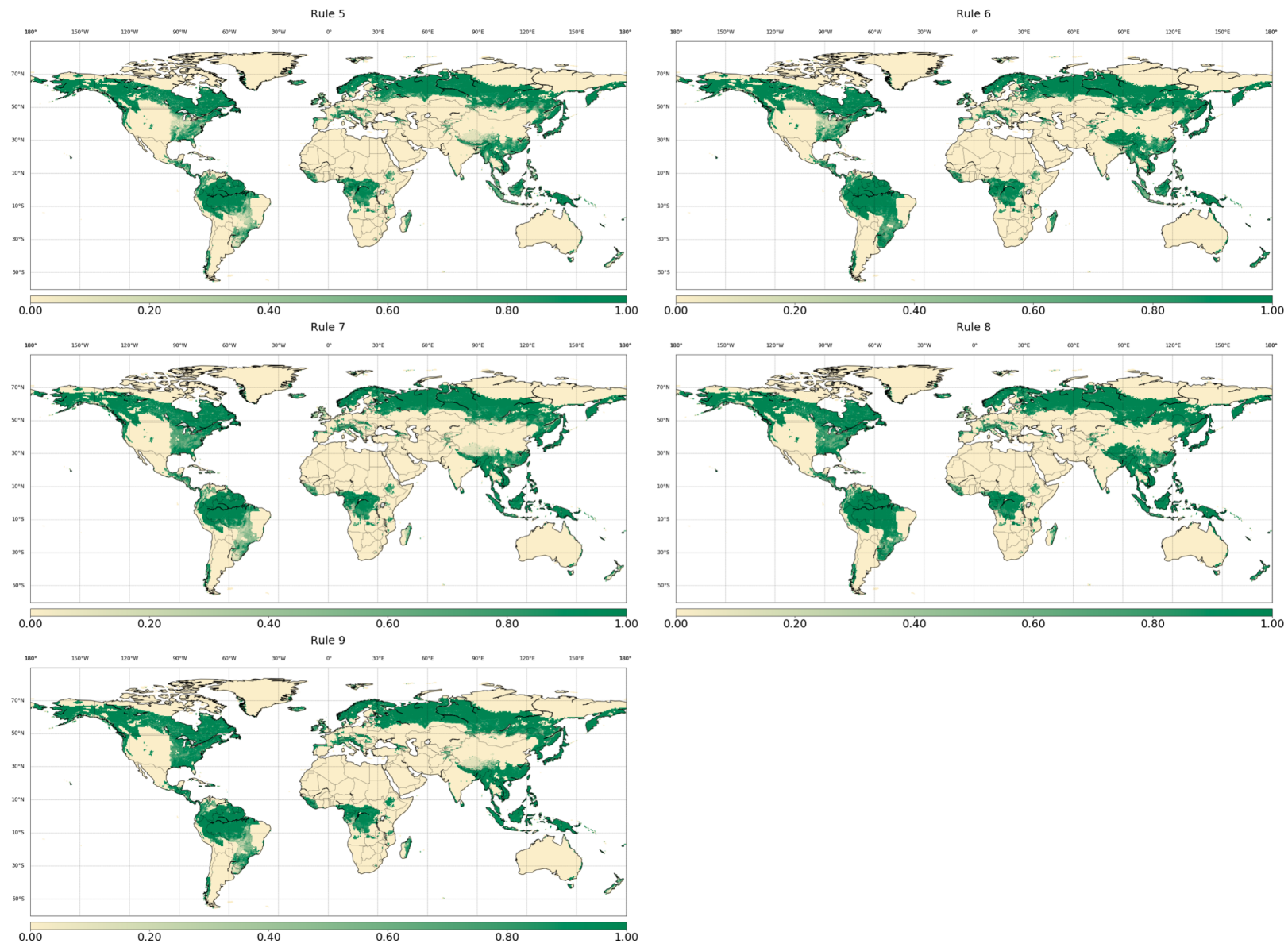

Figure S6. Forest cover in 2000 from the Rules 5-9 respectively. 

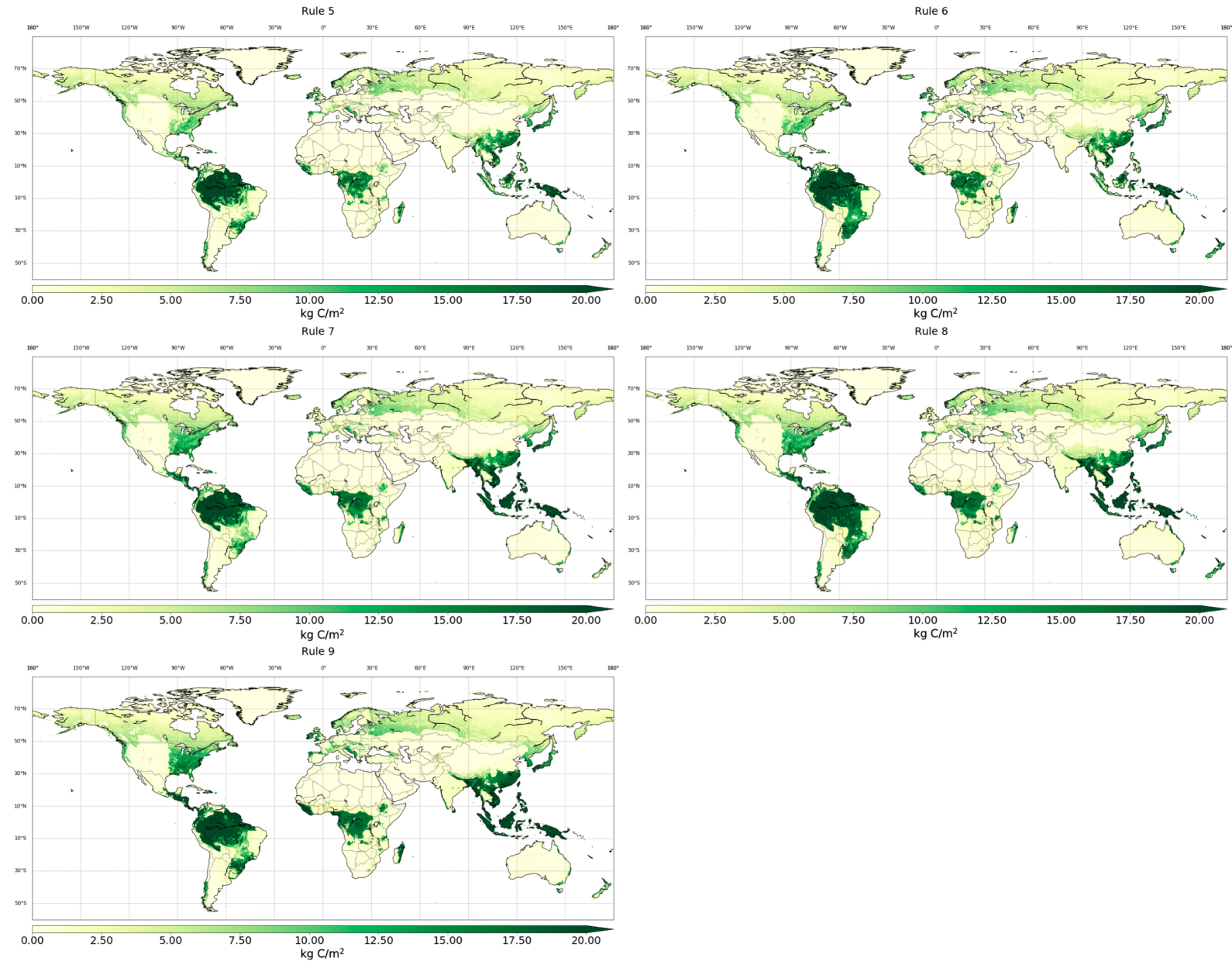

Figure S7. Global carbon density (above- and below-ground) maps estimated by Rules 5-9 respectively. 